\title{
HTLV-I associated uveitis in central Japan
}

\author{
Kaori Goto, Kozo Saeki, Masayuki Kurita, Shigeaki Ohno
}

\begin{abstract}
Aims/Background-Recently HTLV-I has been shown to cause a kind of endogenous uveitis in south west Japan, where HTLV-I infection is highly endemic. To investigate further the association of HTLV-I infection with the incidence of this uveitis, HTLV-I seroprevalence in central Japan, where HTLV-I infection is not endemic, was studied.
\end{abstract}

Methods-HTLV-I seroprevalence was investigated in 1579 patients with various ocular diseases and 1251 normal volunteers as a younger control group. Then HTLV-I seroprevalence was compared in each group.

Results-Of 1579 patients with various ocular diseases, $38(2 \cdot 41 \%)$ were seropositive. There was a statistically significant difference in HTLV-I seroprevalence between the undefined uveitis group and non-uveitic ocular diseases group ( $\mathbf{p}<0.05$, Yates's correction). However, the seroprevalence in younger patients with undefined uveitis did not differ significantly from that in other groups. As regards the incidence of this type of uveitis, six of $12(50 \%)$ seropositive patients, who were born in south west Japan and had lived in this area for 35 years, developed this undefined uveitis whereas only two of $26(7 \cdot 69 \%)$ seropositive patients in the other areas in Japan developed this uveitis. The difference was statistically significant $(p<0.05$, Fisher's exact probability test).

Conclusion-These results suggest that the incidence of this type of endogenous uveitis could be greatly influenced by environmental or hereditary factors including HLA.

(Br f Ophthalmol 1995; 79: 1018-1020)

Division of

Ophthalmology,

Odawara Municipal

Hospital, 46 Kuno,

Odawara 250, Japan

K Goto

K Saeki

M Kurita

Department of

Ophthalmology,

Yokohama City

University School of

Medicine, 3-9 Fuku-

ura, Kanazawa-ku,

Yokohama 236, Japan

S Ohno

Correspondence to:

Shigeaki Ohno, Departmen of Ophthalmology

Yokohama City University

School of Medicine, 3-9

Fuku-ura, Kanazawa-ku,

Yokohama 236, Japan.

Accepted for publication

18 July 1995 Africa, Melanesia, and the Caribbean isla From the worldwide point of view, Japan is a highly endemic area but the geographical distribution is clustered in the south west of the country. There have been some reports of
HAU in south west Japan, ${ }^{67}$ but there have been few reports of the disease in the other areas in Japan. ${ }^{8}$ Our hospital is located in central Japan where HTLV-I infection is not endemic (Fig 1), and we have investigated HTLV-I seroprevalence in 1579 patients with various ocular diseases and 1251 normal volunteers. The present study, which is mainly descriptive, was undertaken to investigate further the association of HTLV-I infection with the incidence of HAU.

\section{Materials and methods}

All 1579 patients in our study were referred to the ophthalmology division of the Odawara Municipal Hospital between June 1992 and January 1995.

All the patients were Japanese living in central Japan at this time. We also investigated HTLV-I seroprevalence in 1251 normal volunteers aged 20 to 49 years old as a younger control group. The age range was 1-99 years. All blood samples were taken with informed consent. Serological status for anti-HTLV-I antibodies was determined by means of a particle agglutination assay (PA method). An agglutination reaction in patient's serum when diluted more than 16 times was regarded as seropositive. The western blot analysis was also carried out on part of the material to confirm the accuracy of detection of the HTLV-I antibodies.

The ophthalmic examinations included careful determination of the anamnesis including birth places of patients and their families, corrected visual acuity, intraocular pressure by applanation tonometry, slit-lamp biomicroscopy, gonioscopy, indirect ophthalmoscopy, and fluorescein angiography if necessary. The patients who were seropositive for HTLV-I were further examined; peripheral blood analysis, blood chemistry, urine analysis, electrocardiogram, thoracic roentgenogram, neurological tests, and an examination of aqueous humour were performed when needed to detect HTLV-I proviral genome after obtaining informed consent. The assay for HTLV-I proviral genome from the inflammatory cells in the aqueous humour was performed with the polymerase chain reaction (PCR). The PCR primers were $5^{\prime}-7358$ CGGATACCCAGTCTACGTGT 7377-3' (sense) and $3^{\prime}-7516$ GCTACCTGCGCAATAGCCGAG 7496-5' (anti-sense) for $\mathrm{pX}$ region amplification. The PCR product was electrophoresed on a $2 \%$ agarose gel and transferred to nylon membrane. The membrane was hybridised with radioactively labelled oligonucleotide probes: $3^{\prime}$ 7447 AGGTGATCTGATGCTCTGGACAGGTGGCCAGTAGGGCG 7486-5' (antisense) for $\mathrm{pX}$ region. 


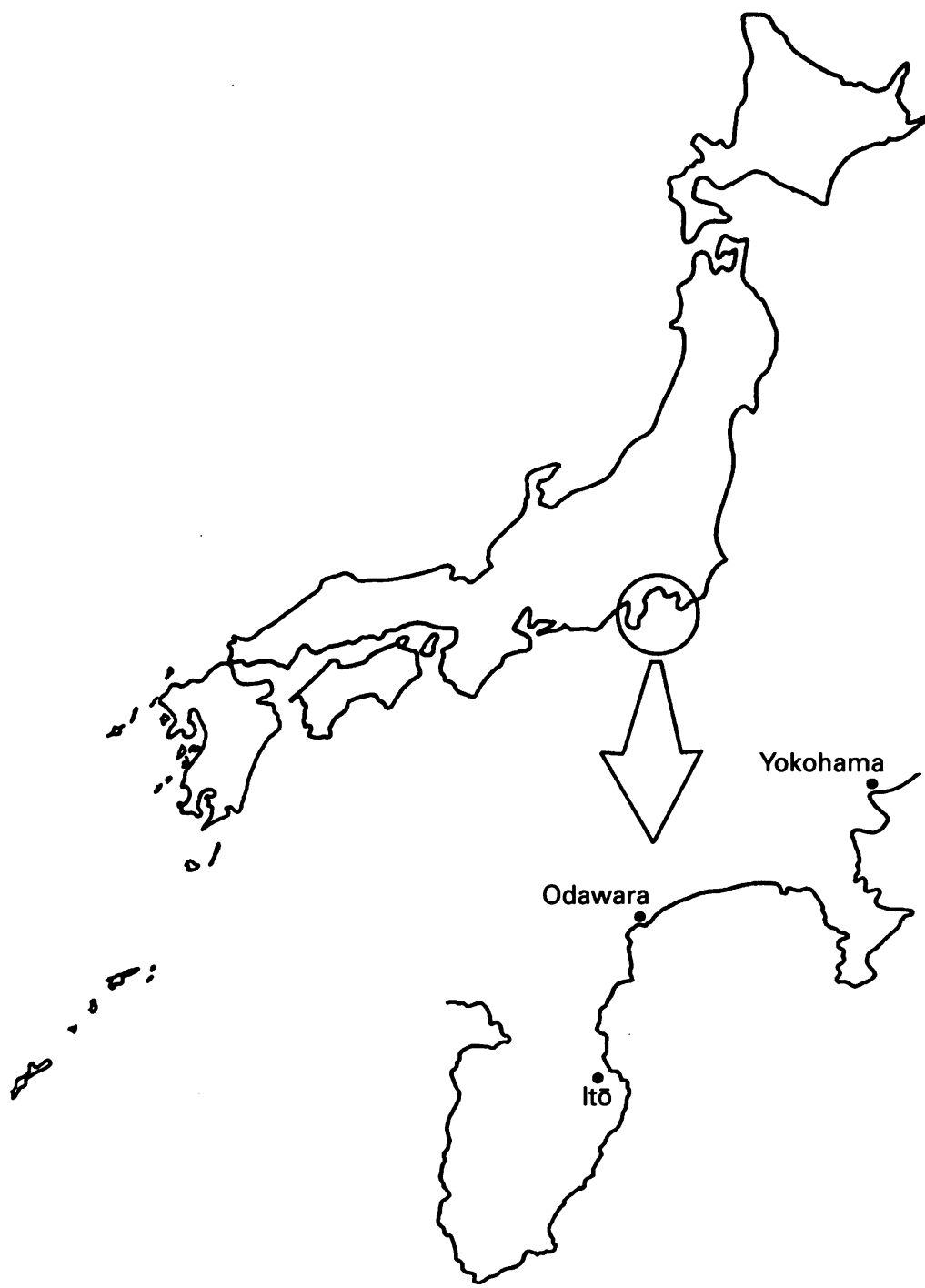

Figure 1 The study was carried out in this area, central fapan, where HTLV-I infection is not endemic.

After careful determination of these results, we divided the patients into three groups and one control group, then compared the seroprevalence of HTLV-I.

Group 1 Patients with defined uveitis that consisted of Behçet's disease, Vogt-KoyanagiHarada's disease, ocular sarcoidosis, herpetic uveitis, Posner-Schlossman syndrome, Fuchs' heterochromic iridocyclitis, ocular toxoplasmosis, and the like.

Group 2 Patients with undefined uveitis that could not be diagnosed even after detailed ophthalmic and systemic examinations.

Group 3 Patients with non-uveitis ocular diseases that included senile cataract, diabetic retinopathy, retinal detachment, glaucoma, retinal vascular occlusion, strabismus, pterygium, and the like.

Group 4 Normal volunteers (aged 20 to 49 years old) as a younger control group.

The Mantel-Haenszel $\chi^{2}$ test was used for statistical comparison.

\section{Results}

Table 1 shows HTLV-I seroprevalence in patients in each groups. The overall seroprevalence of HTLV-I was $38 / 1579(2 \cdot 41 \%)$, and the male:female ratio was $1: 1 \cdot 31$. The seroprevalence of HTLV-I slightly increased with the age of the patients. There were no seropositive patients with haematological or neurological diseases. There was a statistically significant difference in HTLV-I seroprevalence between group 2 (undefined uveitis) and group 3 (non-uveitis ocular diseases) ( $p<0.05$, Yates's correction). Eight seropositive patients with undefined uveitis showed typical clinical features that have been reported as HAU ${ }^{49}$ Additionally, in two seropositive patients with this uveitis, the $\mathrm{pX}$ region of HTLV-I proviral genome was detected from inflammatory cells in the aqueous humour with PCR. The assay for the proviral genome of HTLV-I could not be performed in the other seropositive patients with this uveitis because informed consent could not be obtained.

Table 2 shows HTLV-I seroprevalence in younger patients aged 20 to 49 years old in each group. There was no statistically significant difference in HTLV-I seroprevalence between group 2 and the other groups. Six of $12(50 \%)$ seropositive patients who were born in south west Japan and had lived in this area until they were at least 35 years old, developed HAU whereas only two of $26(7 \cdot 69 \%)$ seropositive patients from other areas in Japan developed HAU (Table 3). The difference was statistically significant $(p<0 \cdot 05$, Fisher's exact probability test).

\section{Discussion}

HTLV-I is well known to cause adult T cell leukaemia, ${ }^{1}$ and HTLV-I associated myelopathy $(\mathrm{HAM}) .^{2}$ Recently there have been some reports that indicate the close association between various organ diseases and HTLV-I infection, ${ }^{1011}$ the term 'HTLV-I

Table 1 HTLV-I seroprevalence in patients with ocular diseases

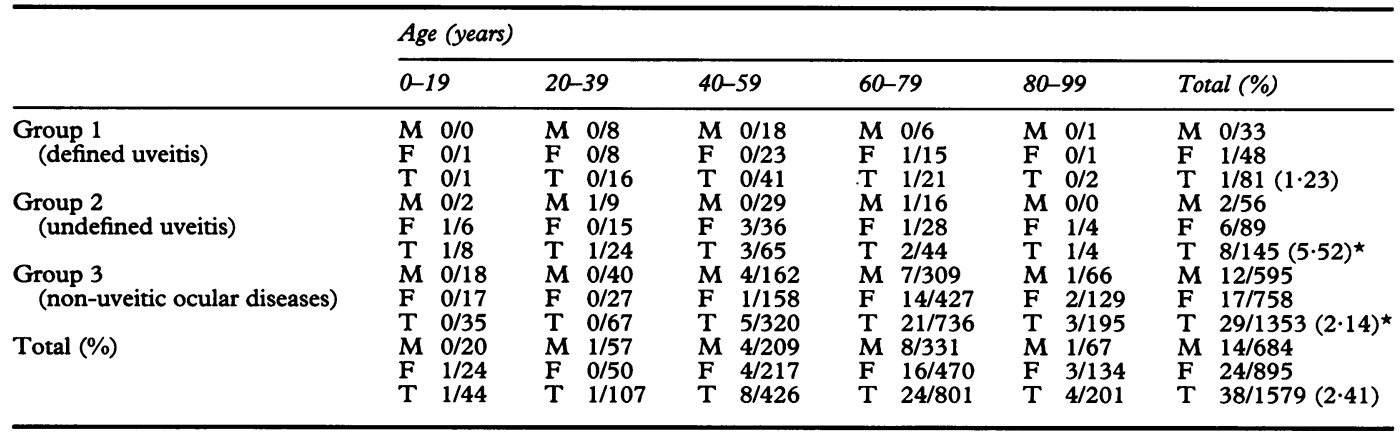

$M=$ male, $\mathrm{F}=$ female, $\mathrm{T}=$ total, ${ }^{\star} \chi^{2}=4 \cdot 88, \mathrm{p}<0 \cdot 05$, Yates's correction. 
Table 2 HTLV-I seroprevalence in younger patients (aged 20 to 49 years)

\begin{tabular}{|c|c|c|c|c|}
\hline & \multicolumn{4}{|c|}{ Age (years) } \\
\hline & $20-29$ & $30-39$ & $40-49$ & Total (\%) \\
\hline Group 1 & $\begin{array}{l}\mathrm{M} 0 / 4 \\
\mathrm{~F} 0 / 0 \\
\mathrm{~T} 0 / 4\end{array}$ & $\begin{array}{l}\mathrm{M} 0 / 4 \\
\mathrm{~F} \quad 0 / 8 \\
\mathrm{~T} 0 / 12\end{array}$ & $\begin{array}{l}\mathrm{M} 0 / 10 \\
\mathrm{~F} 0 / 14 \\
\mathrm{~T} 0 / 24\end{array}$ & $\begin{array}{l}\text { M } 0 / 18 \\
\text { F } 0 / 22 \\
\text { T } 0 / 40(0)\end{array}$ \\
\hline Group 2 & $\begin{array}{l}\text { M } 1 / 6 \\
\mathrm{~F} \quad 0 / 7 \\
\mathrm{~T} \quad 1 / 13\end{array}$ & 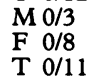 & $\begin{array}{l}\mathrm{M} 0 / 11 \\
\mathrm{~F} 0 / 12 \\
\mathrm{~T} 0 / 23\end{array}$ & 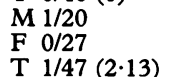 \\
\hline Group 3 & $\begin{array}{l}\mathrm{M} 0 / 21 \\
\mathrm{~F} 0 / 13 \\
\mathrm{~T} 0 / 34\end{array}$ & $\begin{array}{l}\text { M } 0 / 19 \\
\text { F } 0 / 14 \\
\text { T } 0 / 33\end{array}$ & $\begin{array}{ll}M & 1 / 64 \\
\mathrm{~F} & 0 / 54 \\
\mathrm{~T} & 1 / 118\end{array}$ & $\begin{array}{l}\text { M } 1 / 104 \\
\text { F } 0 / 81 \\
\text { T } 1 / 185(0.54)\end{array}$ \\
\hline Group 4 & $\begin{array}{l}\text { M } 1 / 370 \\
\text { F } 1 / 258 \\
\text { T } 2 / 629\end{array}$ & $\begin{array}{ll}\text { M } 2 / 212 \\
\text { F } 1 / 94 \\
\text { T } 3 / 306\end{array}$ & $\begin{array}{ll}M & 3 / 212 \\
\text { F } & 1 / 105 \\
\text { T } & 4 / 317\end{array}$ & $\begin{array}{l}\mathrm{M} 6 / 794 \\
\mathrm{~F} \quad 3 / 457 \\
\mathrm{~T}\end{array}$ \\
\hline
\end{tabular}

$\mathrm{M}=$ male, $\mathrm{F}=$ female, $\mathrm{T}=$ total.

associated complex' has been approved for this association. As regards ocular diseases, a kind of endogenous uveitis has been thought to be associated with HTLV-I infection. From the recent results of epidemiological, clinical, and virological studies, ${ }^{4}$ there seems little doubt that HTLV-I causes a kind of endogenous uveitis (HAU). This new clinical entity is characterised by an intermediate uveitis with vitreous opacities and mild retinal vasculitis, which usually responds well to corticosteroids and is often accompanied by Graves' disease. ${ }^{4}$

So far most cases of HAU have been reported in south west Japan, where HTLV-I infection is highly endemic. ${ }^{346712}$ Of course, this is mainly because that there are many HTLV-I carriers in south west Japan but there are not so many carriers in the other areas in Japan. This study disclosed the existence of patients with HAU even in central Japan, where HTLV-I infection is not endemic. As regards the seroprevalence of HTLV-I in younger patients aged 20 to 49 years, there was no statistically significant difference between the undefined uveitis group and the other groups. But the data in Table 1 show that two of $32(6 \cdot 25 \%)$ patients with undefined uveitis who were younger than 39 years old were seropositive whereas none of 102 patients with non-uveitic ocular diseases and none of 17 patients with defined uveitis were seropositive. Despite no statistically significant difference, these data might suggest a potentially high seroprevalence of HTLV-I in younger patients with undefined uveitis even in central Japan. Interestingly enough, the incidence of HAU in seropositive patients, who were born in south west Japan and had grown up in this area until they were at least 35 years old, is much higher

Table 3 Incidence of HTLV-I associated uveitis (HAU) in seropositive patients

\begin{tabular}{|c|c|c|c|c|}
\hline & $H A U(+)$ & $H A U(-)$ & Total & $\begin{array}{l}\text { Ratio of HAU } \\
\text { in seropositive } \\
\text { patients }\end{array}$ \\
\hline $\begin{array}{l}\text { Seropositive patients from south west Japan } \\
\text { Seropositive patients from the other areas in Japan }\end{array}$ & $\begin{array}{l}6 \\
2\end{array}$ & $\begin{array}{r}6 \\
24\end{array}$ & $\begin{array}{l}12 \\
26\end{array}$ & $\begin{array}{l}50 \% \star \\
7 \cdot 69 \% \star\end{array}$ \\
\hline
\end{tabular}

than that in seropositive patients in the other areas in Japan. This result suggests that the incidence of HAU could be greatly influenced by hereditary background or environmental factors. Regarding the hereditary background, there are at least three ethnically distinguishable populations in Japan: the Ainu in the north, the Ryukyuans in the south west, and the Wajin inhabiting the rest of Japan. ${ }^{13}$ Ainu and Ryukyuans, who share several common physical and genetic traits, are considered to be relatively pure descendants of native Japanese populations inhabiting Japan from the preagricultural Jomon period, more than 2300 years ago. ${ }^{13}$ On the other hand, the Wajin who constitute most of the present population of Japan, are considered to be descendants mainly of post-neolithic immigrants from the mainland in the Yayoi and Kofun eras (300 BC to $\mathrm{AD} 600) .{ }^{13}$ Thus, the origin of residents in south west Japan is thought to be racially different from that in central Japan, and the possibility exists that response modes of individuals to HTLV-I could be hereditarily determined to some degree. Although the detailed mechanism by which HTLV-I infection and this endogenous uveitis are associated is not clear, it is considered that HTLV-I infected $\mathrm{T}$ lymphocytes could play an important role in the immunopathogenesis. Further environmental and molecular biological studies including HLA are needed to clarify the exact mechanisms underlying the incidence of HAU.

1 Yoshida M, Seiki M, Yamaguchi K, Takatsuki K. Monoclonal integration of human T-cell leukemia provirus in all primary tumours of adult $\mathrm{T}$-cell leukemia suggests causative role of human T-cell leukemia virus in the disease. Proc Natl Acad Sci USA 1984; 81: 2534-7.

2 Osame M, Usuku K, Izumo S, Ijichi N, Amitani H, Igata A et al. HTLV-I associated myelopathy, a new clinical et al. HTLV-I associated my

3 Ohba N, Matsumoto M, Sameshima M, Kabayama Y, Nakao $\mathrm{K}$, Unoki $\mathrm{K}$, et al. Ocular manifestations in patients infected with human T-lymphotropic virus type I. fpn f Ophthalmol 1989; 33: 1-12.

4 Mochizuki M, Watanabe T, Yamaguchi K, Yoshimura K, Nakashima S, Shirao $M$, et al. Uveitis associated with human T-cell lymphotropic virus type I. Am f Ophthalmol 1992; 114: 123-9.

5 Blattmer WA. Epidemiology of HTLV-I and associated diseases. In: Blattner WA, ed. Human retrovirology: diseases. In: Blattner WA, ed. Human retro

6 Nakao K, Matsumoto M, Ohba N. Seroprevalence of antibody to HTLV-I in patients with ocular disorders. $\mathrm{Br} \mathcal{F}$ Ophthalmol 1991; 75: 76-8.

7 Yoshimura K, Mochizuki M, Araki S, Miyata N, Yamaguchi K, Tajima $\mathrm{K}$, et al. Clinical and immunologic features of human T-cell lymphotropic virus type 1 uveitis. Am f Ophthalmol 1993; 116: 156-63.

8 Goto K, Saeki K, Kurita M, Ijima Y, Miyake A, Ohno S. HTLV-I seroprevalence in patients with undefined uveitis in central Japan. Ipn $\mathcal{F}$ Ophthalmol 1994; 38: 175-7.

9 Ohba N, Nakao K, Isashiki Y, Kaminagayoshi T, Sonoda S Yashiki S, et al. Clinical features of HTLV-I associated Yashiki S, et al. Clinical features of HTLV-I associated
uveitis determined in multicenter collaborative study. $f_{p n}$ uveitis determined in multicenter

10 Maruyama I, Tihara J, Sakashita I, Mizoguti R, Mori S, Usuku K, et al. HTLV-I associated bronchopneumonopathy - a new clinical entity? Am Rev Resp Dis 1988; 137; 46.

11 Nishioka K, Maruyama I, Sato K, Kitajima I, Nakajima Y, Osame $\mathbf{M}$. Chronic inflammatory arthropathy associated with HTLV-I. Lancet 1989; 1: 441.

12 Nakao $K$, Ohba $N$, Matsumoto $M$. Noninfectious anterior uveitis in patients infected with human T-lymphotropic virus type I. $尹$ pn $₹$ Ophthalmol 1989; 33: 472-81.

13 Ishida T, Hinuma Y. The origin of Japanese HTLV-I. Nature 1986; 322: 504 . 